\title{
THE IMPORTANCE OF PARAPHYLETIC GROUPS IN MAMMALIAN PALEOBIOLOGY.
}

JANIS, Christine, Division of Biology and Medicine, Brown University, Providence, RI 02912, U.S.A.

The introduction of cladistic techniques in phylogenetic systematics have revolutionized many concepts in mammalian taxonomy: most notably, many early groups have been relegated to the status of paraphyletic or polyphyletic assemblages (e.g. the "Condylarthra" or "stem ungulates" and the "Proteutheria" insectivorans.). While it is important to recognize truly polyphyletic groups (e.g. the "Amblypoda" or Paleogene "pachyderm" analogs), all non-monophyletic groups are now commonly assigned to a similar "wastebasket" status, rendering all events associated with their evolution as "pseudo-events" on the grounds of taxonomic impurity.

I am uncomfortable with this tendency for two reasons. The first is philosophical. Monophyly is a time-dependent system of classification: all taxa were monophyletic at their inception and the more successful (i.e. generative) ones must inevitably pass into paraphyly. Cladistic taxonomy claims to be independent of stratigraphic bias, but seemingly has no problem with using an arbitrary cut-off point in the geological record (the Recent) as a means of imposing taxonomic nomenclature. The second is for practical reasons concerning information contained in many of these paraphyletic taxa that is relevant to issues other than phylogenetic systematics.

I examine closely the evolutionary histories of early Paleogene "miacoid" carnivores and late Paleogene "gelocid" artiodactyls. The extinction of miacoid species in the Late Eocene (giving rise to families of larger, apparently more actively hunting carnivores) and the extinction of gelocid species in the Late Oligocene (giving rise to families of larger ruminants apparently better equipped to ingest and process fibrous vegetation) were both coincident with major climatic and environmental changes. The change from non-seasonal to seasonal climates in the Northern hemisphere in the late Eocene may have influenced a change in predator adaptive strategies; likewise, the drying trend and spread of more open habitats in the early Neogene may have influenced ruminant foraging strategies. I submit that while not all paraphylectic groups may be useful in this fashion, at least in the above instances much paleobiological information is lost if these groups are dismissed because of their paraphyletic status: their demise reflects not artificial "pseudoextinction" but rather a real loss of archaic adaptations in a changing world. 